\title{
Article \\ Blockchain-Based Solutions in Achieving SDGs after COVID-19
}

\author{
Ahmet Faruk Aysan ${ }^{1, *(\mathbb{D}}$, Fouad Bergigui ${ }^{2} \mathbb{D}$ and Mustafa Disli ${ }^{1}(\mathbb{C}$ \\ 1 College of Islamic Studies, Hamad Bin Khalifa University, Qatar Foundation, Doha 34110, Qatar; \\ mdisli@hbku.edu.qa \\ 2 SDI Global Consult, Dover, DE 19901, USA; f.bergigui@sdi.world \\ * Correspondence: aaysan@hbku.edu.qa
}

\section{check for} updates

Citation: Aysan, A.F.; Bergigui, F.; Disli, M. Blockchain-Based Solutions in Achieving SDGs after COVID-19. J. Open Innov. Technol. Mark. Complex. 2021, 7, 151. https://doi.org/ 10.3390/joitmc7020151

Received: 9 April 2021

Accepted: 7 June 2021

Published: 9 June 2021

Publisher's Note: MDPI stays neutral with regard to jurisdictional claims in published maps and institutional affiliations.

Copyright: (c) 2021 by the authors. Licensee MDPI, Basel, Switzerland. This article is an open access article distributed under the terms and conditions of the Creative Commons Attribution (CC BY) license (https:// creativecommons.org/licenses/by/ $4.0 /)$.

\begin{abstract}
In this paper, we attempt to explore the extent to which the hard won development gains over the last several years could be reversed due to the unfolding COVID-19 global pandemic, how we can reboot the global response to accelerate the SDGs in times of uncertainties, and most importantly how to turn the recovery into an opportunity to build back better and more resilient economies. To do so, we examine the case of blockchain as one of the emerging innovative work-streams in development practices that could lead the way forward and pave the path for new developmental narratives as we all navigate the uncharted territories of the new digital age. This paper provides useful insights about the underlying dynamics underpinning the adoption of blockchain backedsolutions for sustainable development, and it showcases some of the promising use-cases being developed through trial-and-error experiments by its early adopters. The paper offers a deep dive into a burgeoning development practice in search of disrupting business-as-usual to solve increasingly complex development challenges by mainstreaming innovations such as blockchainenabled solutions to rethink the ways in which development solutions are being delivered across the SDG spectrum. This work points to the significant potential of blockchain technology as a game changer in solving some of the most pressing issues hindering the global recovery post Covid-19 to transition towards greener and more inclusive economies. Nevertheless, we also stress that the hype-cycle behind the "let's blockchain it" trend does not mean that blockchain-backed solutions are necessarily superior to other alternatives which might be less costly and less technical in nature. Development practitioners prototyping and implementing blockchain-based solutions for sustainable development can utilize these insights and discussions to make informed decisions in their journey to harness the disruptive potential of blockchain alone or in tandem with other emerging technologies in the new world of business as unusual.
\end{abstract}

Keywords: SDGs; Covid-19; innovation; blockchain; development

JEL Classification: O16; O19; O35; P16; Q01; Q56

\section{Introduction}

The primary advantage of blockchain is its ability to resolve trust issues without a central third party [1]. The COVID-19 pandemic has brought unprecedented uncertainty to every sector, including the financial services industry. From this perspective, blockchain technology has the potential to reinstitute trust by facilitating the protection of data, simplification of service delivery, clarification of outcome measures, and accountability [1] According to Gartner [2], the estimated business value of blockchain technology will reach $\$ 176$ billion by 2025 before accelerating to $\$ 3.1$ trillion by 2030 . Nonetheless, despite its potential, blockchain has failed to deliver on its promises. It is expected that with the maturity of the technology and the related wider adoption, blockchain will foster successful disruptions [3]. This is consonant with the need to activate regulatory reforms and initiate the necessary cultural and organizational transformations. 
Since the adoption of the Sustainable Development Goals (SDGs) in 2015, many people's lives have reportedly changed for the worse [4]. If new technologies such as blockchain are going to contribute to solving the puzzle, there have to be adequate tools, methodologies, and standards to navigate the blockchain hype-cycle approach towards a rational narrative that is evidence-based. Despite blockchain's promising potential, the reality can be challenging: there are not enough data, blockchain-backed applications for social impact are understudied, and claims that blockchain-backed solutions can yield superior results when compared to other alternatives are yet to be supported by evidence. While we can agree that blockchain has a promising potential to trigger disruptive innovations, we can also agree that the technology is not mature yet and that there is still a gap in terms of approaches and tools to develop blockchain use cases, evaluate blockchain applications, monitor experiments, mitigate associated risks, and manage organizational changes to galvanize innovation-readiness within organizations considering to adopt blockchain technology and run use case experiments [3]. It is only by filling the existing gaps that we can make a stronger case for using blockchain as an SDG accelerator.

This study aims to fill this gap by analyzing numerous applications of blockchain implementations and categorizing them under the SDG that they contribute more to. This approach is relatively new and much needed in the literature. Often-times, blockchain applications are analyzed separately without relating them to a specific SDG. However, by analyzing a comprehensive list of blockchain applications and relating them with selected SGDs, we aim to guide blockchain enthusiasts to be inspired with the new developmental ideas and thereby come up with their blockchain solutions for their community developments. As far as we know, this holistic approach in assessing the various blockchain applications has not been tried before.

Our overall findings reveal that there are very practical blockchain applications exercised in different parts of the world. However, especially after the COVID-19 pandemic, several use cases have the potential to be replicated in different parts of the world where digital solutions are gaining importance with all sorts of Fintech and blockchain applications. The world is passing through a big digital transformation. Being in the middle of this transition, learning the narratives of each blockchain application and relating these narratives with the SDGs is the main objective of this paper. Sustainability and SDGs need these new narratives for reshaping the post-Covid world.

The organization of the paper is as follows. In Section 2, we describe the methodology used in this study. Section 3 presents the results of this study. In this Section, we first provide the analysis of a database. Subsequently, we present a literature review. After a short description of digitalization and SDGs, we delve into explaining various blockchain applications and assess their potential for replication to reach the SDGs by 2030. We particularly focus on certain SDGs that will likely benefit more from the blockchain technology, namely SDG1-5, SGD8-9, and SDG16-17. In Section 4, we depict our policy conclusions based on the evidences studied.

\section{Methodology and Taxonomy}

In this section, we navigate the disruptive waves brought by blockchain-powered solutions to exploring examples of experimental cases applicable to most of the 17 SDGs. We structure our research efforts and findings into various experimentation zones in line with the SDGs, while focusing on specific acceleration areas, to have a closer look at areas where blockchain-backed solutions can have a greater impact as we are heading towards the uncharted territories of the post-pandemic era while eyeballing the finish line in the race to meeting the SDGs by 2030. To do so, from one side we performed an in-depth literature review of blockchain-backed experiments, based on the available literature at the time of conducting this work, to examine their actual or potential contributions to the SDGs. This review is mainly based on grey literature (such as industry reports and white papers) given the recent appearance of blockchain use cases that facilitate SDGs. The grey literature is particularly suitable for our study purposes [5]: first, the industry was substantially 
involved in blockchain technology before academia and hence has had more time to properly evaluate its ramifications. Secondly, industry literature, albeit fragmented, tend to treat Blockchain technology in a holistic manner, which offers the wide viewpoint required to determine what capabilities it promises to deliver. From the other side, this broader literature review was then complemented by a focused deep dive using academic literature and datasets featuring blockchain projects for social impact. Although they have a limited number of entries, such datasets provide useful insights on the geographical dynamics and thematic trends associated with the contribution made by blockchain-enabled solutions to the SDGs. The deep dive analysis was conducted using both the Blockchain Ledger Impact database [6] and literature review.

As explained above, to provide a wider picture beyond the available datasets on blockchain and SDGs giving their limitations, we conducted a wider literature review, the results of which were structured into relevant experimentation zones, that are aligned with most of the 17 SDGs, namely SDG1-5, SGD8-9, and SDG16-17. Due to the novelty of this experimentation, an explorative approach is adopted to process compelling use cases that are aligned with the SDGs. Most of the selected use cases are not sourced from the database of Goldstein and Tillemann [6]. We also acknowledge that some of the use cases might have a duplicate implementation. For this reason, we made a qualitative selection of a given blockchain use case based on its contribution to a focus SDG $([5,7,8]$ follow a similar procedure). Corbin and Strauss [9] argue that a qualitative method is preferred when academic research is still in its infancy and when there is a need for a holistic approach to the phenomena being studied. In doing so, we follow the approach of [10] and selected compelling use cases in the SDG development process when there is a need to: (1) remove third-parties in value exchange; (2) produce a tamper-resistant record of transaction that is trusted by all stakeholders; and (3) reduce operational costs and frictions in the value creation. By doing so, we are able to map 26 use cases according to their SDG focus.

\section{Results}

\subsection{Database Analysis}

Figure 1 shows a breakdown by region of the cumulative numbers of the SDGs to which blockchain projects for social impact contribute based on 71 entries listed in the Blockchain Ledger Impact database. This database was chosen given its focus on SDGs and the relevance of the blockchain experiments listed. This visualization suggests that East Asia and Pacific comes first as the region where blockchain projects contribute to the largest number of SDGs [6]. While the map itself offers much-needed insights into the dynamics of the contribution made by blockchain-enabled solutions to the SDGs, it is only based on a limited number of blockchain projects for social impact $(n=71)$ and hence falls short of providing the full picture. Blockchain-powered solutions remain largely understudied, which stresses the need for reliable sources of data to study how blockchain projects deliver, or do not deliver, social impact on the ground [6]. Such insights are critical learning tools for organizations and individuals alike in an exciting but demanding journey to develop blockchain-backed solutions for social good. 


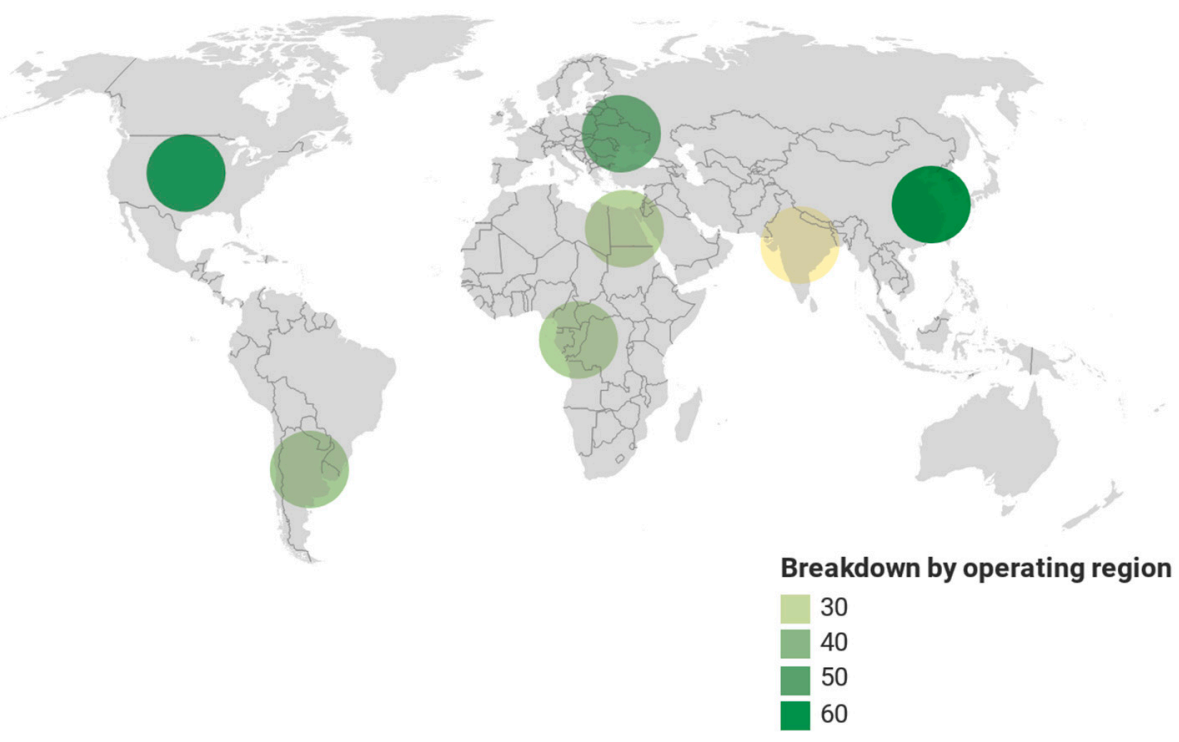

Figure 1. Map showing the contribution of blockchain projects to the SDGs per region. Source: Created by the authors based on data from [6].

As shown in Figure 2, SDG 16 (Peace, justice, and strong institutions) topped the list of the SDGs addressed by blockchain projects based on 71 entries listed in the Blockchain Impact Ledger [6].

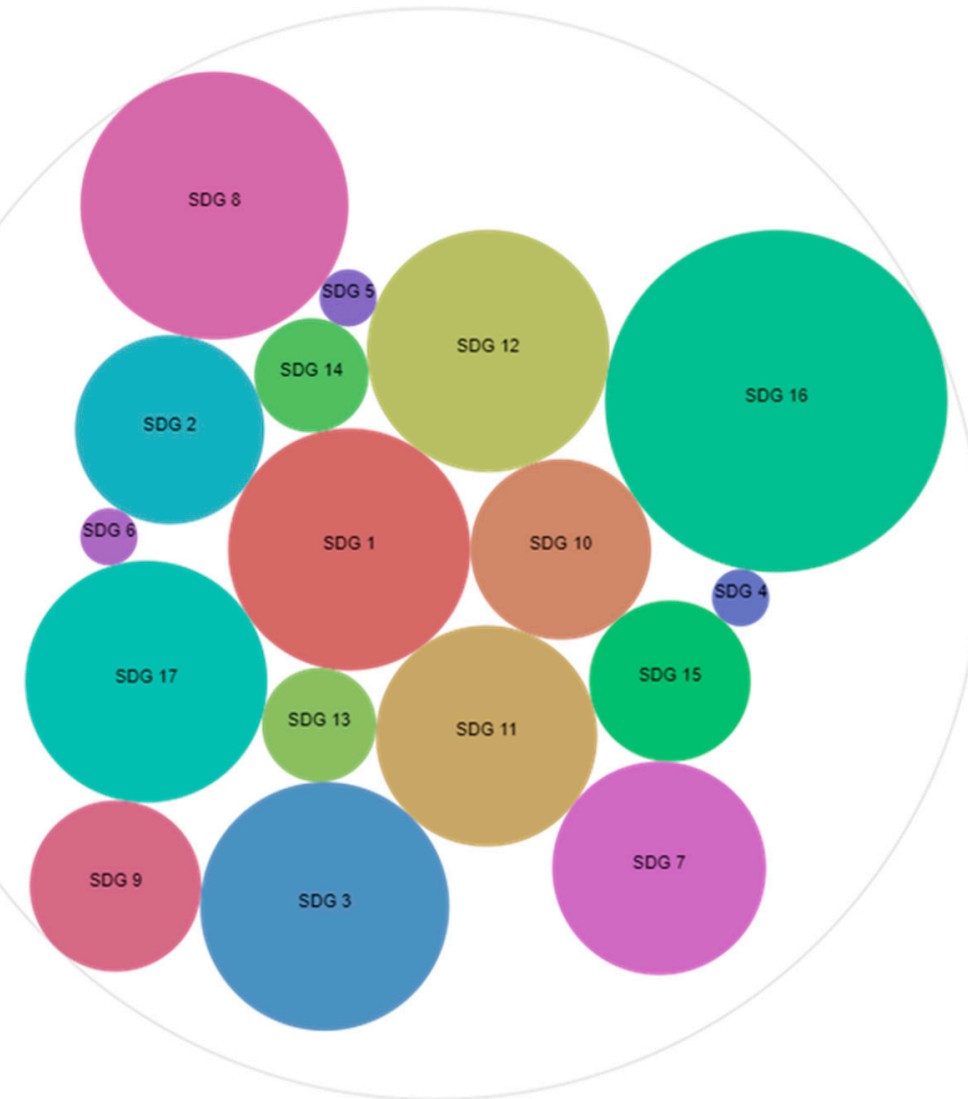

Figure 2. Blockchain projects addressing each SDG. Source: Created by the authors based on data from [6].

It comes as no surprise to see blockchain-enabled applications primarily deployed to address governance matters to tackle issues of transparency, fraud, and other unethical 
behaviors within a wide array of sectors within society. Earlier findings suggest that the scope for blockchain projects for social impact is still in its infancy as most projects are less than two years old. Ethereum is reportedly the most popular blockchain platform, and deploying the technology itself happens to be a multi-stakeholder process with projects consulting with three-five partners on average during product design and deployment [11].

\subsection{Literature Review}

Studies that connect blockchain technology with the achievement of SDGs are in its infancy and are typically concentrated on a limited number of commonly exclusive applications [12]. For example, Adams et al. [13] analyze the role of blockchain as a facilitator of social and environmental initiatives and therefore a contributor to SDGs. Zwitter and Herman [14] discuss the prospective humanitarian aid implications of the blockchain ecosystem. Horner and Ryan [15] explore the potential of blockchain by presenting four usecases in the domains of fair trade, accountability, climate actions, and policy mapping. [16] and [17] analyze the role of blockchain in carbon trading. Franca et al. [18] propose a social token based blockchain to improve solid waste management. Along global supply chains, blockchain has the potential to boost transparency, increase traceability, and reduce transaction costs [19]. Combinations of blockchain and other innovative technologies such as Internet of Things (IoT) can enhance circular economies through informed decision making across sectors such as electrical and electronic wastes [20]. Blockchain-backed information systems can improve collaboration among shipping and logistics firms [21]. A scientometric review of 9151 articles and reviews from 2007 to 2021 identified blockchain technology among the emerging trends in sustainable supply chain management [22]. In the energy sector, blockchain could be combined with other advanced technologies to reduce industrial energy consumption and increase energy efficiency [23]. Blockchain is also among the mix of enabling technologies that can advance smart mobility to address demographic needs in a an increasingly populous globe [24]. Blockchain use cases in the education sector have the potential to evolve into a universally accepted standard for improved academic transcripts [25]. In the construction sector, blockchain technology combined with Building Information Modeling (BIM) can support the sustainable design and construction of buildings as part of the development of smart urban infrastructure [26]. Blockchain can also play a role in the preservation and authorization of digital content in museums, thus contributing to the protection and valorization of intangible assets and cultural heritage [27]. Based on the available literature, there are multiple experiments, where tests are being conducted to explore the proof of concept to develop blockchainbacked solutions and address some of the most pressing challenges in global development. The fundamental question that comes to mind is how distributed ledger technologies can be useful in solving a given situation, which implies changing the narrative to rethink innovative ways out of the problem. For instance, to address identity-related issues, blockchain solutions were designed to provide digital economic identities [28] or open identity systems [29]. To ensure traceability and equity along supply-chains, blockchain applications are experimented with to document the cocoa's from the Amazonian farms in Ecuador to the grocery stores in the UK [30], to trace tuna fish from catch to consumers in Indonesia [31], to trace the authenticity of diamonds [32], or to track minerals [33]. In the field of energy, blockchain solutions are tailored to produce solar energy in Moldova using solar-coins [34], or support the Cedar forest in Lebanon using Cedar-coins [35]. In the field of governance, blockchain applications are used in Estonia to run a digitalized e-government system on blockchain to ensure the security of government registers [36]. In South Korea, blockchain solutions are tested to improve government services such as public safety, welfare, and transportation [37]. Another experiment is looking into building peer-to-peer voting platforms to ensure transparency and accuracy [38]. The list goes on and on to include various blockchain applications with relevance to global development such as copyright, social media, retail, or real estate. 
From this overview, it can be observed that the literature examining the relationship between blockchain and SDGs is fragmented without an integrative approach that unravels some of the best use cases across several SDG targets.

\subsection{Taxonomy of Use Cases}

As mentioned in the methodology section, we follow a qualitative approach to align blockchain use cases with their SDG focus. The results of the broader literature are structured into relevant experimentation zones that are aligned with the majority of the 17 SDGs, namely SDG1-5, SDG8-9, and SDG16-17. In what follows, we will describe in brief 26 compelling use cases mapped according to their SDG focus.

\subsubsection{SDG1: End Poverty in All Its Forms Everywhere}

With regards to eradicating poverty, for instance, in 2015 during the transition from the MDGs to the SDGs, there were still about 736 million people surviving on less than USD 1.90 per day with more than $25 \%$ of the world's populations living on USD 3.20 and almost 50\% living below USD 5.50 daily [39]. In 2017, there were some 1.7 billion adults worldwide with no banking account, however two-thirds of unbanked adults did have a mobile phone [40]. Although wealthier adults are more likely to own a phone and have access to the internet in contrast with their poorer counterparts, financial inclusion can be improved to lift the world's poorest and most vulnerable out of poverty by leveraging the new generation of financial services including blockchain-based solutions that could be accessed through mobile phones and internet. While it might not be profitable for the traditional banking system to offer services below a certain threshold, by processing micro-transactions via the blockchain the technology can connect smallholders and enable those usually overlooked to engage for instance in micro-trade or micro-lending. The tokenization of assets is disrupting the financial industry by making it more accessible, faster, cheaper, and easier [41].

In the Asia Pacific, the Asian Development Bank engaged Everest, a blockchain-based decentralized platform [42], to enable money transfer operators from Australia, New Zealand, and Samoa to process cross border payments through the blockchain [43]. The Everest platform in the Samoan Central Bank supports verification through biometrics, e-wallets, and compliance reporting including "Know Your Customer" and "Anti-Money Laundering" [44]. A similar project is taking place in Indonesia to facilitate cross-border remittance transactions along the Indonesia-Europe corridor in partnership with Bank Rakyat Indonesia [45]. Another example comes from East Africa, where Kenya's famous and largely imitated mobile money system M-Pesa has reportedly lifted 194,000 households out of poverty, about $2 \%$ of the total households in Kenya [46], despite its siloed nature which limits its impact. This is where blockchain technology can come into play to allow systems like M-Pesa to seamlessly interact with digital wallets, traditional bank accounts, and remittance services [47]. This is the case of Mojaloop, the Swahili word for "One loop" [48], an open-source global platform that can support real-time and interoperable digital payment systems in developing countries to increase financial inclusion [49], and consequently uplift the world's poor out of poverty [50]. The platform enables an 'internet of payments' through secure, low-cost, and interoperable payments using different components to bring bank accounts together with mobile money wallets and merchants in one loop, identify transaction accounts, ensure instant and irrevocable payment as well as protection against fraud [51].

3.3.2. SDG2: End Hunger, Achieve Food Security and Improved Nutrition and Promote Sustainable Agriculture

Following a steady decline over the last decades, hunger is on the rise with more than 820 million people suffering from hunger in 2019, with Africa being the most hit continent showing the highest prevalence of undernourishment [52]. In contrast, about $14 \%$ of the food produced globally is lost during production or along the supply chain between harvest and retail [53], and about a third of the food produced for human consumption 
is lost or wasted, representing an estimated global volume of food wastage of about 1.6 gigatons [54] and putting its economic cost at about $\$ 1$ trillion every year [55]. Blockchainbased solutions can disrupt the global food value chain by tackling some of its inefficiencies. One way to optimize the supply-chain and tackle the opacity of the global food industry is by increasing transparency to sustainably mitigate food loss and wastage. Addressing the supply chain in the food industry will, given the interlinked nature of SDGs, also contribute to reducing the carbon footprint of agriculture (SDG13), preserve biodiversity and ecosystems by reducing water consumption and soil contamination through the use of fertilizers and other chemicals (SDGs 14 \& 15), and control the spread of food-borne diseases (SDG3).

Blockchain can be the platform to apply algorithms to match offer and demand while using valuable insights from behavioral sciences to predict consumption patterns, agriculture data, and remote sensing. This can enable the right amount of fresh harvest to make an optimal journey from the field, through processing to retail, by tracking every step of the value chain including the production and harvesting techniques, storage protocols, transportation, processing, and distribution. The same thinking can be applied to humanitarian food aid, for instance, to ensure the transparency of cash transfers and enable refugees to purchase food. AgriLedger, created under $48 \mathrm{~h}$ in a hackathon then tweaked to become part of the Agtech landscape [56], is a seed-to-customer blockchain-enabled platform offering end-to-end traceability along agricultural value chains [57] which aims to democratize agricultural data using blockchain [58]. A pilot project with the World Bank along the fruits value chain in Haiti allows buyers to scan a QR code to tell the story of the fresh mango produce by revealing the tree it came from, where it was packaged and how it was transported, and the costs incurred at each milestone. The immutable data related to registration, certification, and sale documents are made accessible on the web and via smartphone [57]. In Ethiopia's Limu region, Token, a new consumer brand of coffee or rather a blockchain coffee, is a blockchain-powered solution that aims to connect coffee growers and consumers [59]. While such an application contributes to transparency and traceability, it may also strengthen ownership. Token coffee bags come with a token that is worth 50 cents of a Euro which represents its marketing cost. Coffee consumers can then use the CrypCore platform [60] to invest their tokens whether by discounting the price of the coffee they bought, by supporting coffee producers, or the brand itself. The proof of concept was based on an initial experiment covering $60,000 \mathrm{~kg}$ of coffee produced by smallholder communities, and the tokenization was initially tested with about 100 individuals [61]. Again, this shows how the SDGs are interlinked. By paying a more just and equitable price to smallholder farmers, they can afford the cost of production while preserving their social and environmental capitals in the long run.

\subsubsection{SDG3: Ensure Healthy Lives and Promote Well-Being for All at All Ages}

In the healthcare industry, blockchain use cases range from record management to surveillance systems, streamlining communication, tracking outbreaks, managing crises, tracking medical supply chains, preventing zoonotic diseases, and providing genomic services. Mutual health plans and insurance firms can offer accessible insurance products to low-income groups and expedite payments to participants by eliminating paperwork and easing verification of claims. For example, Alipay's Xiang Hu Bao is an online blockchainbacked mutual aid platform that complements premium health insurance plans. The online system publicly discloses claims on the blockchain and facilitates the digital authentication of official documents [62]. Its coverage includes 100 critical illnesses, there are no premiums to be paid, participants share the cost of claims made and contribute to payouts, and the approved claims may entitle participants to a one-time payout of up to roughly US $\$ 44,000$ [63]. In Hong Kong, Blue Cross Asia-Pacific Insurance shows that blockchain eases the pressure on health care systems by processing over 1000 simultaneous transactions in one second [64]. In Estonia, a blockchain-backed solution by Guardtime will enable an audit trail through the lifecycle of patients' records making data virtually impossible to 
manipulate [65]. Patientory is a platform to store, manage, and transfer private health information including through the execution of smart contracts on the Ethereum blockchain [66]. In the field of genomics, Nebula Genomics provides a blockchain platform to conduct free DNA sequencing in exchange for consent for the data to be used in research [67].

During the global pandemic of COVID-19, as the world struggled to cope with a health crisis with far-reaching consequences on the economy and long-lasting impacts on different aspects of human life, different blockchain-based solutions emerged. Panic buying and inflation for instance could be interpreted as signs of poor trust in institutions in charge of keeping people safe. In supply chains, for instance, blockchain was used to trace and confirm the source of products and information to fight counterfeit production and misinformation. It can also play a role in minimizing price inflation by ensuring a transparent cost distribution. Acoer created the HashLog data visualization engine, a blockchain-enabled dashboard to track and map out vital health information and enable professionals in the healthcare and life science space track and visualize the outbreak [68]. Shanzong launched a blockchain-based platform to ensure the efficiency and transparency of donations; it tracked which donations were made from money to medical equipment, and how they were matched and delivered during the Coronavirus pandemic [69]. Other blockchain-powered solutions during COVID-19 include e-learning platforms [70] and decentralized learning certificates [71].

\subsubsection{SDG4: Ensure Inclusive and Equitable Quality Education and Promote Lifelong Learning Opportunities for All}

In the areas of education and lifelong learning, blockchain can be used to store records, secure students' identities and credentials, transfer credits, increase the efficiency of existing business-processes, process students' payments and grants, and protect and track the use of the intellectual property for educational content. This will reduce costs and fraud by skipping manual verification of degrees and transcripts while increasing efficiencies through automated smart contracts [72]. ODEM, a blockchain-powered education platform, offers a decentralized education scheme within which students, educators, and schools operate autonomously while enjoying full control over their educational data and employment records [73]. It provides a secure solution for integrated enrollment, learning management, in addition to blockchain-backed digital learning certificates, which can be used to track progress and achievements [74]. Such a blockchain-based solution empowers students to take full ownership of their educational records. Not only can they select courses according to employer demand, but they also will not have to wait for hard diplomas to be delivered to apply for jobs or to replace originals if they get lost or damaged [75]. Digital Academic Credentials, an MIT incubated project [76], allow students to receive tamper-proof and verifiable digital diplomas on their smartphones using the Blockcerts Wallet app on the bitcoin blockchain [77]. Using the same open-source code in the Asia Pacific, the University of Melbourne issued recipient-owned digital credentials on the blockchain in an attempt to tackle the challenges raised by increasingly itinerant students and workforce [78].

\subsubsection{SDG5: Achieve Gender Equality and Empower All Women and Girls}

Gender equality is not just about SDG5, it is central to the achievement of all the SDGs. Empowering women and men will not only contribute to the global economy and lift entire families and rural communities out of poverty but also accelerate national efforts on different frontlines by promoting all sorts of gender-smart interventions in education, economy, and other areas pertaining to the wider spectrum of the Sustainable Development Agenda. Blockchain can disrupt the way financial services are provided to the most vulnerable groups which remain underbanked and largely excluded from the traditional financial markets. More specifically, women in developing countries are most likely to earn their income from the informal sector and suffer from financial illiteracy, mobility constraints, insufficient collaterals, or even the lack of identification. Blockchain can bridge the gender gap in cross-border payments and empower women and men to fulfill their financial independence. UN Women is exploring blockchain-enabled solutions 
to support the humanitarian response targeting women and girls in emergencies such as refugees to secure their identity, medical, and asset ownership records [79]. Among the innovations showcased is SPENN [80], a digital wallet that enables users to interact with each other using their smartphones to receive, save, transfer, and spend money [81]. In refugee camps, such solutions can remove the need for women to carry physical cash and empower them to have greater control over their financial resources. In Vietnam, the World Bank is testing a blockchain-backed pilot to support women entrepreneurs by proving asset ownership, verify production values, and establish digital identities [81]. From Norway, a blockchain application called VipiCash was developed not only to securely transfer money and reduce transfer costs but also to enable women in the refugee camps to decide on how it will be spent independently from men in their families. By locking the money for a specific use, for instance, to buy groceries or pay for school fees, a Congo born winner of the Nordic Startup Awards wanted to help refugees in Malawi to avoid frictions between men and women and ensure that remittances are used for what they are intended for [82]. Hiveonline, a company using blockchain-backed solutions to support underserved microbusinesses access credit and markets by creating a trusted history for formal reputation, has launched its community finance platform eARZIKI in Niger, targeting village savings and loans groups to enable women to grow their businesses through formal reputation and access to finance [83]. It digitizes money and identities which boost the trustworthiness of micro-entrepreneurs seeking to borrow funds. Activities such as attending meetings and payments made are recorded to prove that the borrowers reliable to the lenders and vice versa, meaning that lenders are also rated based on their reliability and how they treat customers [84]. It is true, however, that the gender divide extends its branches over the digital walls to the crypto space, with the management of crypto-firms being mostly male-dominated and few women trading in crypto-assets. The transformational change will also need to start from within the crypto industry itself. There is a need to invest in the skillsets women and other social groups from all walks of life need to enter the crypto space as coders, developers, data scientists, mentors, or managers. Diversity in Blockchain, an NGO working to empower individuals to equally engage with the blockchain technology, highlighted the lack of inclusion in its State of Diversity and Inclusion in Blockchain report [85]. The report recommended in its call for action to implement best practices such as training on unconscious biases, measuring and reporting diversity and inclusion, and creating policies of openness and trust [86]. Ironically, while blockchain can foster trust, it also needs to bolster policies of trust, and while it can empower women and men to challenge gender inequalities, it also needs to become gender-responsive.

3.3.6. SDG8: Promote Sustained, Inclusive, and Sustainable Economic Growth, Full and Productive Employment, and Decent Work for All

Economic growth and employment can also benefit from disruptive technologies such as Blockchain, which is seen by some as the new infrastructure for building efficient ecosystems to spark innovation across various economic sectors and achieve growth, enable countries to tap into their demographic dividends, create qualified jobs in the crypto sphere and facilitate recruitment processes. In the Background Check industry, the current business model is relatively slow, involving multiple personnel and neither guarantees successful screenings nor the security of sensitive data. Verification, a blockchain-based platform, offers a new way for corporations and recruitment agents to headhunt the most promising candidates through a blockchain-backed and direct exchange of employment records and academic references. The platform also supports the verification of various educational records while providing useful analytical tools to track important insights related to the employment markets [87].

3.3.7. SDG9: Build Resilient Infrastructure, Promote Inclusive and Sustainable Industrialization, and Foster Innovation

Blockchain applications can spark innovation across a wide spectrum of industries from automotive to banking, health care, insurance, media and entertainment, retail and 
consumer goods, travel, and transportation to name just a few examples. In the automotive industry, for instance, cars can become much more than vehicles in the rapidly evolving landscape of smart mobility and evolve into some sort of connected software on wheels. This is the case made by IBM and partners developing a blockchain-based eWallet to handle cashless payments from tolls to electric charging, but also between cars and the use of a vehicle's trunk to securely drop a package [88].

3.3.8. SDG 11: Make Cities and Human Settlements Inclusive, Safe, Resilient, and Sustainable

The next-generation infrastructure for smart cities can be built on blockchain layers to come up with disruptive solutions to tackle pressing issues such as waste management, protection of personal data, strategic urban planning, green energy, public participation, low carbon transportation, water management, health systems, traffic management, and the security of IoT devices. In Malta, the Government is developing a platform for transport and logistics to proactively predict growth, balance routes and systems, and optimize services based on passenger' behavior by using blockchain-backed data flows such as GPS systems and journey tracking [89]. In Estonia, the government created the concept of e-residency, invested in digital IDs and cybersecurity, and established data embassies abroad with blockchain-backed State registries including healthcare, property, succession, and business in addition to the digital court system and the state Gazette [90].

3.3.9. SDG 16: Promote Peaceful and Inclusive Societies for Sustainable Development, Provide Access to Justice for All, and Build Effective, Accountable, and Inclusive Institutions at All Levels

It comes as no surprise to see blockchain-enabled applications primarily deployed to address governance matters and to tackle issues of transparency, fraud, and other unethical behaviors within a wide array of sectors within society. These are the very foundations to ensure peaceful and inclusive societies, accountability, and justice. Given the secure and immutable nature of the blockchain technology, SDG 16 topped the list of the SDGs addressed by blockchain projects based on 71 entries listed in the Blockchain Impact Ledger [6]. Civil, a blockchain-backed network for journalists, news organizations, and investors, offers a combination of tokens and voting rights to its shareholders. Participants hold a blockchainbased token to govern the network, they can vote and propose rules. The platform also features a micropayment enabling journalists to receive donations from readers in the form of tokens which forms a substantial part of their salaries and makes reporters also shareholders of Civil [91,92]. Blockchain use cases in journalism can be targeted solutions to store data or hybrids introducing cryptocurrency which may disrupt the way newsrooms and reports work [92]. Some argue however that blockchain will not save journalism and that the hype around the technology is driving incomprehensible applications [93]. Another promising potential for the deployment of blockchain applications is in the area of public procurement. An accountable, inclusive, and transparent public procurement process will promote competition and reduce corruption risk [94]. For example, to increase external oversight, the Columbian government provided a proof-of-concept for the validity of an Etherium-based blockchain procurement process to select vendors for Columbia's school meals program, Programa de Alimentación Escolar, which has been affected by various corruption scandals [95]. Although the results from this pilot study are promising, more research and experimentation are still needed to evaluate the effectiveness of blockchain to increase public procurement efficiency.

3.3.10. SDG 17: Strengthen the Means of Implementation and Revitalize the Global Partnership for Sustainable Development

One key issue to achieve the Sustainable Development Goals (SDGs) is indeed financing for development, which remains way below expectations especially in developing countries. While public finance and Official Development Assistance will not be enough to fill in the financing gap, achieving the SDGs cannot be done without securing business 
financial flows. Blockchain-backed solutions can improve the financial infrastructure for international development and humanitarian aid. Trócaire Ireland, a development agency, simultaneously transferred $€ 10,000$, via Trócaire Rwanda, to Caritas Rwanda using the Disberse platform, and $€ 10,000$ via their regular banking channel. The transfer via Disberse incurred no additional charges; the parallel transfer through the banking system incurred at least one additional charge of EUR35. In this pilot, Disberse did not charge transaction fees, but a small fee will be considered in the future. There was clear tracking of the Disberse financial transfers. The transactions were transparent and accountable to each stakeholder in the transaction chain. Transactions were timestamped and created a viewable trail. There were challenges in comparing time savings measured by the number of working days it took funds to move from Trócaire Ireland to Caritas Rwanda, the banking system took six days, while Disberse took five days [96].

Table 1 summarizes the blockchain-enabled solutions mapped out in this paper in terms of their potential contributions to the SDGs.

Table 1. Blockchain-enabled solutions according to their SDG focus.

\begin{tabular}{|c|c|c|}
\hline SDG in Focus & Blockchain-Enabled Solutions & What Is It Used for? \\
\hline \multirow{3}{*}{ SDG1 } & Asian Development Bank \& partners & Cross border payments \\
\hline & M-Pesa & Mobile money system \\
\hline & Mojaloop & Digital payment system \\
\hline \multirow[b]{2}{*}{ SDG2 } & AgriLedger & Seed-to-customer platform \\
\hline & Token & Coffee value chain \\
\hline \multirow{7}{*}{ SDG3 } & Xiang Hu Bao & Mutual aid platform \\
\hline & Blue Cross Asia-Pacific & Health insurance \\
\hline & E-Estonia & Patients' records \\
\hline & Patientory & Health records \\
\hline & Nebula Genomics & DNA sequencing \\
\hline & HashLog & Data visualization engine \\
\hline & Shanzong & Donations platform \\
\hline \multirow{3}{*}{ SDG4 } & ODEM & Education platform \\
\hline & MIT Media Lab & Digital credentials \\
\hline & University of Melbourne & Digital credentials \\
\hline \multirow{4}{*}{ SDG6 } & SPENN & Digital wallet \\
\hline & World Bank pilot in Vietnam & Asset ownership \\
\hline & VipiCash & Money transfer \\
\hline & eARZIKI & Community finance platform \\
\hline SDG8 & CVerification & Records and references \\
\hline SDG9 & IBM and partners & Ewallet \\
\hline \multirow[b]{2}{*}{ SDG11 } & Government of Malta & Transport and logistics \\
\hline & Government of Estonia & Data registries \\
\hline \multirow{2}{*}{ SDG16 } & Civil & Network for journalism \\
\hline & Programa de Alimentación Escolar & Public procurement \\
\hline SDG17 & Disberse platform & Money transfer \\
\hline
\end{tabular}

Source: Authors.

\section{Concluding Remarks and Discussions}

Could blockchain be a game-changer as an SDG accelerator under a new normal scenario? Or is it a hype that is driven by high expectations for its applications in the new digital age? We argue that the power of blockchain can be effectively harnessed to deliver significant progress towards achieving the SDGs. Nevertheless, we also argue that there are limitations to what can be done, hence the need to nuance that development professionals cannot solve all the issues around the SDGs with blockchain, and that implementation choices to design and implement blockchain-enabled solutions should be rigorously justified to demonstrate a tangible added-value compared to other alternative solutions which 
might be less costly and less technical. In this regard, the SDG acceleration scorecard proposed by Aysan et al. [3] might provide a useful tool to develop blockchain-based solutions for sustainable interventions.

"Don't over-hype and don't over-promise" remains a key message for individuals and organizations experimenting blockchain-powered solutions in various fields of International Development. In this paper, we aim to add our contribution to further stimulate the discussions within the research community but also among innovation and development practitioners working at the frontlines to raise the double challenge of adapting to the new normal post-pandemic and meeting the SDG targets by 2030.

Certainly, this work provides a good overview of the current state of deployment of blockchain-enabled solutions to solve some of the most pressing development challenges. Yet, more investigations are needed as the hidden part of the blockchain for good iceberg is slowly emerging over time, as the technology is getting mature and as lessons learned are being shared based on the trial-and-error experiments being conducted within various geographies and across a wide range of economic, social, and environmental spectrums. We hope that individuals and organizations working on blockchain-based solutions for sustainable development utilize these insights and discussions to guide their efforts and inform their decisions to harness the disruptive potential of blockchain alone or in tandem with other emerging technologies in the new world of business as unusual.

Author Contributions: Conceptualization, A.F.A., F.B. and M.D.; data curation, A.F.A., F.B. and M.D.; formal analysis, A.F.A., F.B. and M.D.; funding acquisition, A.F.A., F.B. and M.D.; investigation, A.F.A., F.B. and M.D.; methodology, A.F.A., F.B. and M.D.; project administration, A.F.A., F.B. and M.D.; resources, A.F.A., F.B. and M.D.; software, A.F.A., F.B. and M.D.; supervision, A.F.A., F.B. and M.D.; validation, A.F.A., F.B. and M.D.; visualization, A.F.A., F.B. and M.D.; writing-Original draft, A.F.A., F.B. and M.D.; writing-Review \& editing, F.B. and M.D. All authors have read and agreed to the published version of the manuscript.

Funding: This research received no external funding.

Institutional Review Board Statement: Not applicable.

Informed Consent Statement: Not applicable.

Data Availability Statement: Not applicable.

Conflicts of Interest: The authors declare no conflict of interest.

\section{References}

1. Jiang, L. The Age of Trust-The Problem Blockchain Solves That Others Cannot. 2018. Available online: https://medium.com/ swlh/the-age-of-trust-the-problem-blockchain-solves-that-others-cannot-6024ebf47cad (accessed on 24 September 2019).

2. Gartner. Digital Disruption Profile: Blockchain's Radical Promise Spans Business and Society. 2018. Available online: https: //www.gartner.com/en/doc/3855708-digital-disruption-profile-blockchains-radical-promise-spans-business-and-society (accessed on 29 February 2020).

3. Aysan, A.F.; Bergigui, F.; Disli, M. Using Blockchain-Enabled Solutions as SDG Accelerators in the International Development Space. Sustainability 2021, 13, 4025. [CrossRef]

4. Ghosh, J. 3 Obstacles That Stand in the Way of the UN's Sustainable Development Goals. 2019. WEF. Available online: https: / / www.weforum.org/agenda/2019/09/3-obstacles-that-stand-in-the-way-of-the-un-s-sustainable-development-goals / (accessed on 24 May 2020).

5. Ruoti, S.; Kaiser, B.; Yerukhimovich, A.; Clark, J.; Cunningham, R. SoK: Blockchain technology and its potential use cases. arXiv 2019, arXiv:1909.12454. Available online: https:/ /arxiv.org/abs/1909.12454 (accessed on 23 October 2020).

6. Goldstein, D.; Tillemann, T. Blockchain Impact Ledger. 2020. New America. Available online: https://www.newamerica. org/digital-impact-governance-inititiative/blockchain-trust-accelerator/reports/blockchain-impact-ledger/ (accessed on 22 May 2020).

7. Randall, D.; Goel, P.; Abujamra, R. Blockchain applications and use cases in health information technology. J. Health Med. Inform. 2017, 8, 1-17. [CrossRef]

8. Voinea, D.V. Blockchain for Journalism-Potential Use Cases. Soc. Sci. Educ. Res. Rev. 2019, 6, 244-256.

9. Corbin, J.; Strauss, A. Basics of Qualitative Research: Techniques and Procedures for Developing Grounded Theory; Sage Publications: New York, NY, USA, 2014. 
10. Popovic, D.; Avis, C.; Byrne, M.; Cheung, C.; Donovan, M.; Flynn, Y.; Fothergill, C.; Hosseinzadeh, Z.; Lim, Z.; Shah, J. Understanding blockchain for insurance use cases. Br. Actuar. J. 2020, 25, 1-23. [CrossRef]

11. Gregori, B. Blockchain and Social Impact Research: Preliminary Findings. 2019. New America. Available online: https:/ / www.newamerica.org/digital-impact-governance-inititiative/blockchain-trust-accelerator/around-the-blockchainblog/blockchain-and-social-impact-research-preliminary-findings/ (accessed on 23 October 2020).

12. Sinha, A.; Sengupta, T.; Saha, T. Technology policy and environmental quality at crossroads: Designing SDG policies for select Asia Pacific countries. Technol. Forecast. Soc. Chang. 2020, 161, 120317. [CrossRef]

13. Adams, R.; Kewell, B.; Parry, G. Blockchain for good? Digital ledger technology and sustainable development goals. In Handbook of Sustainability and Social Science Research; Springer: Cham, Switzerland, 2018; pp. 127-142.

14. Zwitter, A.; Herman, J. Blockchain for Sustainable Development Goals; \#Blockchain4SDGs—Report 2018; University of Groningen: Groningen, The Netherlands, 2018.

15. Horner, J.; Ryan, P. Blockchain Standards for Sustainable Development. J. ICT Stand. 2019, 7, $225-248$.

16. Kim, S.K.; Huh, J.H. Blockchain of Carbon Trading for UN Sustainable Development Goals. Sustainability 2020, $12,4021$. [CrossRef]

17. Mandaroux, R.; Dong, C.; Li, G. A European Emissions Trading System Powered by Distributed Ledger Technology: An Evaluation Framework. Sustainability 2021, 13, 2106. [CrossRef]

18. França, A.S.L.; Neto, J.A.; Gonçalves, R.F.; Almeida, C.M.V.B. Proposing the use of blockchain to improve the solid waste management in small municipalities. J. Clean. Prod. 2020, 244, 118529. [CrossRef]

19. Mercuri, F.; della Corte, G.; Ricci, F. Blockchain Technology and Sustainable Business Models: A Case Study of Devoleum. Sustainability 2021, 13, 5619. [CrossRef]

20. Magrini, C.; Nicolas, J.; Berg, H.; Bellini, A.; Paolini, E.; Vincenti, N.; Campadello, L.; Bonoli, A. Using Internet of Things and Distributed Ledger Technology for Digital Circular Economy Enablement: The Case of Electronic Equipment. Sustainability 2021, 13, 4982. [CrossRef]

21. Bae, H.-S. The Interaction Effect of Information Systems of Shipping and Logistics Firms and Managers' Support for Blockchain Technology on Cooperation with Shippers for Sustainable Value Creation. Sustainability 2021, 13, 4493. [CrossRef]

22. Su, Z.; Zhang, M.; Wu, W. Visualizing Sustainable Supply Chain Management: A Systematic Scientometric Review. Sustainability 2021, 13, 4409. [CrossRef]

23. Borowski, P.F. Digitization, Digital Twins, Blockchain, and Industry 4.0 as Elements of Management Process in Enterprises in the Energy Sector. Energies 2021, 14, 1885. [CrossRef]

24. Paiva, S.; Ahad, M.A.; Tripathi, G.; Feroz, N.; Casalino, G. Enabling Technologies for Urban Smart Mobility: Recent Trends, Opportunities and Challenges. Sensors 2021, 21, 2143. [CrossRef] [PubMed]

25. Caldarelli, G.; Ellul, J. Trusted Academic Transcripts on the Blockchain: A Systematic Literature Review. Appl. Sci. 2021, 11, 1842. [CrossRef]

26. Liu, Z.; Chi, Z.; Osmani, M.; Demian, P. Blockchain and Building Information Management (BIM) for Sustainable Building Development within the Context of Smart Cities. Sustainability 2021, 13, 2090. [CrossRef]

27. Wang, Y.-C.; Chen, C.-L.; Deng, Y.-Y. Museum-Authorization of Digital Rights: A Sustainable and Traceable Cultural Relics Exhibition Mechanism. Sustainability 2021, 13, 2046. [CrossRef]

28. BanQu. Dignity through Identity. 2019. Available online: https://banqu.co/the-tech/ (accessed on 10 May 2020).

29. Uport. Open Identity System for the Decentralized Web. 2019. Available online: https://www.uport.me/ (accessed on 10 May 2019).

30. AltFinLab. A Fair Deal for Ecuadorian Cocoa Farmers. 2019. Available online: https://altfinlab.org/blog/a-fair-deal-forecuadorian-cocoa-farmers (accessed on 10 May 2020).

31. Provenance. From Shore to Plate: Tracking Tuna on the Blockchain. 2016. Available online: https://www.provenance.org/ tracking-tuna-on-the-blockchain (accessed on 10 May 2020).

32. Everledger. Do You Know Your Diamond? 2018. Available online: https:/ / diamonds.everledger.io/ (accessed on 10 May 2020).

33. Khatri, Y. Volkswagen to Track Minerals Supply Chains Using IBM Blockchain. 2019. CoinDesk. Available online: https: / / www.coindesk.com/volkswagen-to-track-minerals-supply-chains-using-ibm-blockchain (accessed on 10 May 2020).

34. SolarCoin. Produce One Megawatt Hour, Get One Free SolarCoin. Incentivizing a Solar Powered Planet. 2019. Available online: https:/ / solarcoin.org/ (accessed on 10 May 2020).

35. AltFinLab. Adopting a Cedar Tree Brings Diaspora Money Home. 2019. Available online: https://altfinlab.org/blog/adopting-acedar-tree-brings-diaspora-money-home (accessed on 10 May 2020).

36. Sihvart, M. Blockchain—Security Control for Government Registers. 2017. E-estonia. Available online: https:/ /e-estonia.com/ blockchain-security-control-for-government-registers/ (accessed on 30 May 2020).

37. Buck, J. Samsung Wins Public Sector Blockchain Contract for Korean Gov't. 2017. Cointelegraph. Available online: https: / / cointelegraph.com/news/samsung-wins-public-sector-blockchain-contract-for-korean-govt (accessed on 30 May 2020).

38. FollowMyVote. Introducing a Secure and Transparent Online Voting Solution for the Modern Age. 2019. Available online: https: / / followmyvote.com/ (accessed on 10 May 2020).

39. World Bank. Poverty and Shared Prosperity 2018. 2018. Available online: https://www.worldbank.org/en/publication/povertyand-shared-prosperity (accessed on 10 March 2020). 
40. World Bank Group. The Global Findex Database 2017. 2017. Available online: https://globalfindex.worldbank.org/node (accessed on 3 March 2020).

41. Laurent, P.; Chollet, T.; Burke, M.; Seers, T. The Tokenization of Assets is Disrupting the Financial Industry. Are You Ready? Deloitte. 2019. Available online: https://www2.deloitte.com/content/dam/Deloitte/lu/Documents/financial-services/lutokenization-of-assets-disrupting-financial-industry.pdf (accessed on 30 May 2020).

42. Everest. Fintech Elevating Humanity. 2020. Everest. Available online: https:/ / everest.org/\#the-project (accessed on 30 May 2020).

43. Rheeney, A. Firm Engaged to Support Money Transfer Operators. 2019. Samoa Observer. Available online: https://www. samoaobserver.ws/category/article/40817 (accessed on 30 May 2020).

44. Vilar, H. Everest to Supply KYC Platform in Samoa for Cross-Border Transactions. 2019. Fintech Futures. Available online: https: / / www.fintechfutures.com/2019/03/everest-to-supply-kyc-platform-in-samoa-for-cross-border-transactions/ (accessed on 30 May 2020).

45. Ledger Insights. Everest Partners with Bank Rakyat Indonesia for Remittances Using Blockchain. 2020. Available online: https:/ / www.ledgerinsights.com/blockchain-remittance-everest-bank-rakyat-indonesia/ (accessed on 30 May 2020).

46. Suri, T.; Jack, W. The Long-Run Poverty and Gender Impacts of Mobile Money. 2016. Available online: https://www.jefftk.com/ suri2016.pdf (accessed on 30 May 2020).

47. Morris, D.Z. Google and Gates Foundation to Help Spread Digital Payments in Developing Countries. 2020. Fortune. Available online: https:/ / fortune.com/2020/05/06/google-gates-foundation-digital-payments-developing-countries/ (accessed on 30 May 2020).

48. Mojaloop. Open Source Software Empowering Organizations to Create Interoperable Digital Payment Systems to Increase Financial Inclusion. 2020. Mojaloop Foundation. Available online: https:/ / mojaloop.io/the-mojaloop-foundation-launches-as-acharitable-nonprofit-organization-to-advance-the-financial-inclusion-mission-of-mojaloop/ (accessed on 30 May 2020).

49. Hunter, P. Nonprofits and Tech Companies Unite to Launch Mojaloop Foundation for Financial Inclusion. 2020. IBS Intelligence. Available online: https://ibsintelligence.com/ibs-journal/ibs-news/nonprofits-and-tech-companies-unite-to-launch-mojaloopfoundation-for-financial-inclusion/ (accessed on 30 May 2020).

50. ModusBox. Announcing Mojaloop.io-An Open-Source Software Platform for Financial Inclusion to Uplift the World's Poor. 2017. Available online: https:/ / modusbox.com/announcing-mojaloop-io-an-open-source-software-platform-for-financial-inclusionto-uplift-the-worlds-poor/ (accessed on 30 May 2020).

51. Cable, E. Webinar: Introduction to Mojaloop from the Gates Foundation. 2018. Mifos. Available online: https://mifos.org/blog/ intro-to-mojaloop/ (accessed on 10 April 2020).

52. FAO. The State of Food Security and Nutrition in the World. 2019. Available online: http://www.fao.org/3/ca5162en/ca5162en. pdf (accessed on 16 March 2020).

53. FAO. The State of Food and Agriculture. 2019. Available online: http://www.fao.org/3/ca6030en/ca6030en.pdf (accessed on 16 March 2020).

54. FAO. Food Wastage Footprint, Impacts on Natural Resources. 2013. Available online: http://www.fao.org/3/i3347e/i3347e.pdf (accessed on 16 March 2020).

55. FAO. Food Wastage Footprint, Full Cost Accounting. 2014. Available online: http:/ /www.fao.org/3/a-i3991e.pdf (accessed on 16 March 2020).

56. AgriLedger. Are You Ready for the Agtech Revolution? 2017. Available online: http://www.agriledger.io/about/ (accessed on 14 May 2020).

57. Leveille, G. World Bank Blockchain Pilot Sows Fresh Narrative for Haiti's Farmers. 2019. Open Access Government. Available online: https:/ /www.openaccessgovernment.org/world-bank-blockchain-haitis-farmers/61205/ (accessed on 30 April 2020).

58. Aspioneer. AgriLedger, Democratizing Agriculture Data Using Blockchain. 2018. Available online: https://aspioneer.com/ agriledger-democratizing-agriculture-data-using-blockchain/ (accessed on 30 April 2020).

59. Bryman, H. Fully Blockchained Coffee Brand Token Invites Consumers into the Matrix. 2018. Daily Coffee News. Available online: https:/ / dailycoffeenews.com/2018/07/11/fully-blockchained-coffee-brand-token-invites-consumers-into-the-matrix/ (accessed on 30 April 2020).

60. KrypC. Unlock the Potential of Blockchain Innovation. 2019. Available online: https:// krypc.com/ (accessed on 30 April 2020).

61. Food Ingredients First. Blockchain Coffee: Token Builds a “Community-Owned" Coffee Brand. 2018. Food Ingredients First. Available online: https://www.foodingredientsfirst.com/news/blockchain-coffee-token-builds-a-community-owned-coffeebrand.html (accessed on 30 April 2020).

62. Ant Financial. Alipay's Xiang Hu Bao Aims to Provide Online Mutual Aid to 300 Million People in the Next 2 years. 2019. Ant Financial Services Group. Available online: https:/ /www.antfin.com/newsDetail.html?id=5caeea701d75d2d441311eba (accessed on 31 May 2020).

63. Ledger Insights. Alipay's Blockchain Mutual Health Plan Attracts 50 Million Users. 2019. Available online: https://www. ledgerinsights.com/alipays-blockchain-mutual-health-plan-attracts-50-million-users/ (accessed on 31 May 2020).

64. Tran, S. Insurance Firms in China and Hong Kong Count on Blockchain to Fast Track Wuhan Coronavirus Claims Amid Outbreak. 2020. Blockchain News. Available online: https:/ / blockchain.news/analysis/insurance-firms-in-china-and-hong-kong-counton-blockchain-to-fast-track-wuhan-coronavirus-claims-amid-outbreak (accessed on 31 May 2020). 
65. E-estonia. eHealth Authority Partners with Guardtime to Accelerate Transparency and Auditability in Health Care. 2016. Available online: https://e-estonia.com/ehealth-authority-partners-with-guardtime-to-accelerate-transparency-andauditability-in-health-care/ (accessed on 31 May 2020).

66. Patientory. Your Health, at Your Fingertips. 2020. Available online: https:/ / patientory.com/ (accessed on 31 May 2020).

67. Morris, N. Nebula Launches "free" DNA Sequencing Blockchain Platform. 2018. Ledger Insights. Available online: https: //www.ledgerinsights.com/nebula-launches-dna-blockchain-platform/ (accessed on 31 May 2020).

68. Nasr, J. Acoer: We Track Coronavirus on Blockchain. 2020. Digital Asset Live. Available online: https://digitalasset.live/2020/0 2/05/blockchain-coronavirus-interview/ (accessed on 31 May 2020).

69. Zhang, J. China Start-Up Launches Blockchain-Based Platform to Improve Donation Efficiency Amid Virus Crisis. 2020. Available online: https:/ / www.scmp.com/tech/blockchain/article/3050461/china-start-launches-blockchain-based-platform-improvedonation (accessed on 31 May 2020).

70. Humayun, M. Blockchain-Based Secure Framework for e-Learning during COVID-19. Ind. J. Sci. Technol. 2020. [CrossRef]

71. Hayward, A. Coronavirus Is Driving Education onto Blockchain. 2020. Available online: https://decrypt.co/24785/coronavirusis-driving-education-onto-blockchain (accessed on 31 May 2020).

72. Cognizant. Blockchain Goes to School. 2019. Available online: https://www.cognizant.com/whitepapers/blockchain-goes-toschool-codex3775.pdf (accessed on 2 April 2020).

73. ODEM. The ODEM Trust Network. 2020. Available online: https://odem.io/odem-trust-network/ (accessed on 30 April 2020).

74. ODEM.IO. ODEM Helps Fight Coronavirus by Offering Its Blockchain Education and Credentialing Platform for Free. 2020. PR Newswire. Available online: https: / / www.prnewswire.com/news-releases/odem-helps-fight-coronavirus-by-offering-itsblockchain-education-and-credentialing-platform-for-free-301019428.html (accessed on 30 April 2020).

75. Maaghul, R. It's 2019, and You Should Be in Control of Your Education. 2019. Available online: https://blogs.odem.io/odemblockchain-technology-and-unlocking-your-education (accessed on 30 April 2019).

76. MIT Media Lab. What We Learned from Designing an Academic Certificates System on the Blockchain. 2016. Medium. Available online: https:/ / medium.com/mit-media-lab/what-we-learned-from-designing-an-academic-certificates-system-onthe-blockchain-34ba5874f196 (accessed on 30 April 2020).

77. Trachy, A.; Durant, E. Digital Diploma Debuts at MIT. 2017. Available online: http://news.mit.edu/2017/mit-debuts-securedigital-diploma-using-bitcoin-blockchain-technology-1017 (accessed on 30 April 2020).

78. University of Melbourne. University of Melbourne to Issue Recipient-Owned Blockchain Records. 2017. Available online: https:/ / about.unimelb.edu.au/newsroom/news/2017/october/university-of-melbourne-to-issue-recipient-ownedblockchain-records (accessed on 30 April 2020).

79. UN Women. UN Women and Partners to Pilot Blockchain Technology in Humanitarian Action. 2018. Available online: https:/ / www.unwomen.org/en/news/stories/2018/2/news-event-blockchain-technology-and-humanitarian-action (accessed on 31 May 2020).

80. Blockbonds. SPENN. 2019. Available online: https://blockbonds.io/spenn (accessed on 31 May 2020).

81. Young, D.; Hammond, A. Can Blockchain Disrupt Gender Inequality? 2018. Available online: https://blogs.worldbank.org/psd/ can-blockchain-disrupt-gender-inequality (accessed on 31 May 2020).

82. UN Women. From Where I stand: Using Blockchain Technology to Empower Women. 2018. UNWomen. Available online: https://www.unwomen.org/en/news/stories/2018/2/from-where-i-stand-olivier-mukuta (accessed on 10 May 2020).

83. Blakstad, S. Launching eARZIKI—Blockchain Financial Inclusion—In Niger with M. Le President. 2019. Hivenetwork. Available online: https:/ / www.hivenetwork.online/2019/07/launching-e-arziki-in-niger-with-m-le-president-de-la-republic/ (accessed on 10 March 2020).

84. CWI. Finalist 2020 Europe. 2020. Cartier Women's Initiative. Available online: https://www.cartierwomensinitiative.com/ candidate/sofie-blakstad (accessed on 31 May 2020).

85. Tinianow, A. Bombshell Report Finds Inclusion Lacking in the Blockchain Industry. 2019. Forbes. Available online: https: / / www.forbes.com/sites/andreatinianow / 2019/12/23/bombshell-report-finds-inclusion-lacking-in-the-blockchainindustry/\#539c25ea9e1c (accessed on 31 May 2020).

86. Joseph, S. State of Diversity and Inclusion in Blockchain. 2019. Available online: https://static1.squarespace.com/static/5a7f13828 a02c7e2df8e6c68/t/5e00f58ccf118b46b6fbd32c/1577121230490/The+State+of+Diversity+and+Inclusion+in+Blockchain.pdf (accessed on 31 May 2020).

87. CVerification. Blockchain-Based Recruitment and Background Verification Platform. 2017. Available online: https://icorating. com/upload/whitepaper/v8AtWVXJCAjwZzrLNhVUEJwG3E5VakbMaqIUgtpw.pdf (accessed on 7 May 2020).

88. IBM. Drive Your Automotive Enterprise Forward with IBM Blockchain. 2018. Available online: https://www.ibm.com/ downloads/cas/D9KWXMDW (accessed on 8 May 2020).

89. Omnitude. Omnitude \& The Maltese Govt. 2018. Available online: https://omnitude.tech/omnitude-the-maltese-govt/ (accessed on 8 May 2020).

90. PWC. Estonia-The Digital Republic Secured by Blockchain. 2019. Available online: https://www.pwc.com/gx/en/services/ legal/tech/assets / estonia-the-digital-republic-secured-by-blockchain.pdf (accessed on 8 May 2020).

91. Agora. Bringing Voting Systems into the Digital Age. (Swiss Lab \& Foundation for Digital Democracy). 2019. Available online: https:/ / www.agora.vote/ (accessed on 29 May 2020). 
92. Ivancsics, B. Blockchain in Journalism. 2019. Columbia Journalism Review. Available online: https://www.cjr.org/tow_center_ reports/blockchain-in-journalism.php (accessed on 31 May 2020).

93. Jonah, B.E. Alas, the Blockchain Won't Save Journalism After All. 2018. The New York Times. Available online: https: / / www.nytimes.com/2018/11/01/style/blockchain-journalism-civil.html (accessed on 3 May 2020).

94. Ballard, T. Transparency and Public Procurement; Supplement to the 2011 Annual Statistical Report on United Nations Procurement; UNOPS: Copenhagen, Denmark, 2012; pp. 2-3.

95. Lannquist, A.; Raycraft, R.E. Exploring Blockchain Technology for Government Transparency Public Procurement to Reduce Corruption; Insight Report; World Economic Forum: Geneva, Switzerland, 2020.

96. Start Network. Blockchain-Pilot II Summary of Learnings. 2018. Available online: https://start-network.app.box.com/s/utb8 bq70g2tgo0rb6jgb167tjn9p1huh (accessed on 3 March 2020). 